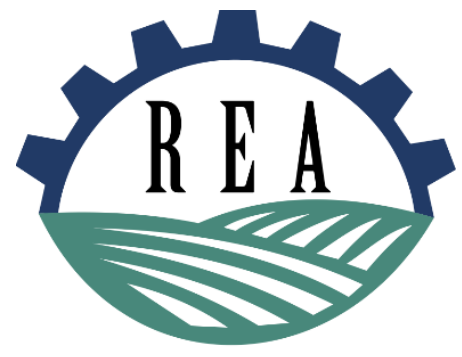

Revista de Economia e Agronegócio - REA ISSN impresso: 1679-1614 ISSN online: $2526-5539$ Vol. 15 | N. 3 | 2017

Emanoel Barros ${ }^{*}$ Yony Sampaio ${ }^{1}$ João Ricardo F. Lima²

1 Universidade Federal de Pernambuco, Programa de PósGraduação em Economia (PPGECON)

2 Empresa Brasileira de Pesquisa Agropecuária - Embrapa Semiárido

* leonamebr@gmail.com

\section{ESTUDO DOS ASPECTOS COMPORTAMENTAIS QUE INFLUENCIAM NA VENDA POR CONTRATOS ENTRE PRODUTORES DE MANGA DO POLO PETROLINA-JUAZEIRO}

\section{RESUMO}

O presente artigo busca identificar os determinantes que influenciam o conhecimento e a utilização de contratos entre os produtores de manga do Polo Petrolina-Juazeiro. Para tanto, foi utilizado um modelo logit multinomial em função da escolha do produtor em "não conhecer o mercado de contratos" ou em "conhecer e não fazer uso desse mercado". A categoria tomada como parâmetro de comparação do modelo foi a relativa aos produtores que declararam "conhecer e utilizar contratos". Em termos de efeitos marginais, os resultados mostram que as propensões a conhecer e a participar do mercado de contratos são ambas aumentadas quando o "produtor médio" passa a ter acesso a assistência técnica e a treinamento. No tocante aos fatores que explicam a estimação logit multinomial, há diferenças nas variáveis, o que aprofunda a compreensão do tema em questão.

Palavras-chave: Agricultura Irrigada; Contratos; Logit.

\section{ABSTRACT}

This article seeks identifying variables that making mango Petrolina/Juazeiro farmers' decide using contracts. For this, we use a multinomial logit model where the producers 'choosing' by non-knowing or by non-use contracts. Results show that producer who use technical assistance and training in your plan of production have a high probability to use the contracts' market There are divergences between variables that explaining the non-knowing and non-using of contracts. In the first model, training, other outlies of protection and propensity to risk increase the probability to knowing contract's market. In the second model, production, association, technical assistance and other debts increase the probability to using contracts.

Keywords: Agriculture Irrigated; Contracts; Logit.

JEL Code: C14; C21; Q13. 


\section{INTRODUÇÃO}

O mercado de contratos é uma ferramenta útil para o setor agrícola, sobretudo quando tem a finalidade de amenizar as variações que certos produtos ou commodities apresentam em seus preços ao longo do tempo. $\mathrm{Na}$ maior parte dos casos, esse mercado consiste no estabelecimento de um acordo formal entre produtores agrícolas e instituições financeiras visando a redução do risco de preços. O caso dos produtores ligados a fruticultura irrigada do Polo Petrolina-Juazeiro é um exemplo diferenciado desse panorama. O mercado de venda por contratos, no contexto do Polo Petrolina-Juazeiro, assume a finalidade básica de garantir preços mais competitivos para produtos que seriam inicialmente vendidos na propriedade do produtor ou em feiras livres.

Nesse escopo, a presente pesquisa busca analisar o mercado de venda por contratos entre os produtores de manga localizados no Polo PetrolinaJuazeiro. Foca-se aqui nas relações contratuais que visam agregar maior valor ao preço da manga, uma vez que a tecnologia disponível aos produtores permite que os mesmos possam adentrar em melhores mercados consumidores.

Como foco do trabalho, busca-se apontar quais fatores comportamentais dos produtores poderiam afetar suas decisões de conhecer e utilizar (ou não utilizar) o mercado de contratos. Referida expectativa deriva de uma série de fatores pormenorizados em estudos como os de Shapiro e Brorsen (1988), Asplund et al. (1989), Turvey e Barker (1990), Makus et al.(1990), Goodwin et Schroden (1994), Penning et Leuthold (2000), Isengildina e Hudson (2001), Sherrick et al. (2003), Lima e Ferreira-Irmão (2004) e Cruz Júnior et al. (2011, 2012), sendo a maior parte desses trabalhos aplicados a análises de commodities negociadas por contratos em mercados futuros, mas que podem ser adaptados ao contexto da manga irrigada do Polo Petrolina-Juazeiro. De maneira geral, esses fatores podem ser divididos em três principais vertentes: (i) características do produtor; (ii) características relativas ao modelo de gestão do negócio; e, (iii) características comportamentais dos produtores ${ }^{1}$.

No caso específico do Polo Petrolina-Juazeiro, as relações pertinentes à troca e aos atributos econômicos dos bens e serviços transacionados na venda por contratos corroboram o estabelecimento de relações contratuais baseadas em promessas antecipadas de compra e venda (contratos consignados). Contratos consignados são frequentes na região pelo fato de a mesma se deparar com um cenário em que existe grande número de produtores agrícolas e pequeno número de empresas exportadoras (menos de 10 empresas), o que leva essas últimas a atuarem como monopsônios. Assim, a celebração desses contratos segue procedimentos e regras estabelecidos por essas empresas visando atender as exigências de produção necessárias à atividade exportadora. A vantagem para o produtor é a obtenção de um

\footnotetext{
1 Os detalhes dos fatores que compõem cada um desses grupos de categorias se encontram na seção "Modelo Empírico" deste trabalho. 
preço mais elevado por unidade de manga. Os procedimentos estabelecidos pelas empresas exportadoras para efetuação desses contratos são dados na seguinte ordem:

a) As empresas exportadoras, mediante visita realizada antes do período de plantio da manga, estabelecem a quantidade específica a ser produzida no lote do produtor;

b) Quinze dias antes do prazo de colheita, as empresas enviam técnicos e agrônomos para averiguarem a evolução do produto. Atingido o padrão de qualidade necessário, a empresa realiza a colheita da produção;

c) A quantidade colhida é acondicionada em veículos climatizados da empresa e encaminhada ao centro de embalagem e preparo da fruta para a exportação. A empresa entrega um recibo ao produtor especificando a quantidade colhida, o preço acordado por unidade de manga e as características particulares do produto (variedade, tamanho, diâmetro, características fitossanitárias, etc.);

d) Decorridos 30 dias da colheita, a empresa realiza o pagamento mediante um cheque nominal ao produtor, de acordo com as especificações contidas no recibo.

Nesse sentido, as questões básicas em torno da análise do presente trabalho se encontram nos seguintes pontos: (i) quais fatores poderiam explicar a venda por contrato junto aos produtores de manga do Polo PetrolinaJuazeiro? (ii) quais, dentre esses fatores, aumentariam a probabilidade de esses produtores conhecerem e/ou aderirem ao mercado de venda por contratos?

Este trabalho, em comparação com os demais referenciados sobre o tema, concentra-se numa análise econométrica da relação contratual consignada, em que o produtor representativo (diferentemente dos produtores de commodities negociadas em bolsas de valores) é caracterizado como um agricultor familiar. Nessa relação, o exportador (que atua como monopsônio) entra como um facilitador, promovendo a inserção do produtor no mercado internacional de manga. Nessa lógica, a relação contratual em estudo difere das relações contratuais comumente estudadas na literatura econômica, podendo a presente pesquisa trazer bons apontamentos para o tema em questão.

Assim, para bem compreender cada um dos pontos enunciados acima, o artigo foi organizado em seis seções, incluindo esta introdução. A Seção 2 apresenta um pequeno panorama do quadro exportador de manga do referido polo, enfatizando sua significância em relação ao mercado exportador brasileiro de manga. Na Seção 3, apresentam-se os seguintes tópicos: i) modelo econométrico; ii) dados utilizados; e iii) modelo empírico utilizado. Os resultados são apresentados na Seção 4 e as principais conclusões, na Seção 5, seguidas, por fim, das referências. 


\section{O CENÁRIO EXPORTADOR DA MANGA DO POLO PETROLINA- JUAZEIRO}

O Polo Petrolina-Juazeiro tem despontado nas últimas décadas como um dos importantes centros exportadores de fruticultura do Brasil. Isso se deve sobretudo às janelas de exportações existentes nos mercados consumidores de frutas no exterior (o que confere uma vantagem comparativa ao Brasil) e à proximidade com os portos de destino (o que representa uma vantagem competitiva à Região Nordeste). A pauta de exportação do Polo PetrolinaJuazeiro tem se concentrado basicamente nas culturas de manga e uva, que apresentam maior valor agregado na região e possuem aceitabilidade nos Estados Unidos e na União Europeia, seus principais mercados.

De acordo com Sampaio (2007), a Região Nordeste produz manga para exportação em basicamente três estados: Rio Grande do Norte (Polo Assu), Pernambuco e Bahia (Polo Petrolina-Juazeiro). Considerando a produção de manga para exportação dos estados de Pernambuco e Bahia, o quadro se mostra ainda mais interessante. De acordo com dados do Ministério do Desenvolvimento e Comércio Internacional (MDCI, 2013), o volume de exportações conjuntas de manga desses dois estados aumentou, entre 2009 e 2012, de 77.430 toneladas para 109.903 toneladas (um acréscimo de aproximadamente $42,00 \%$ ). No tocante à receita adquirida com as exportações de manga, o aumento foi de US\$77,43 milhões, em 2009, para US\$109,90 milhões, em 2012 (equivalente a um percentual adicional de $41,94 \%$ no período).

Para se ter uma ideia da magnitude desse processo exportador, somente no ano de 2012, o volume de produção e o valor da receita apurados correspondiam a cerca de $86,54 \%$ do total da produção de manga exportada pelo Brasil e cerca de $79,87 \%$ da receita adquirida, respectivamente. O Polo Petrolina-Juazeiro responde, portanto, por quase $90 \%$ do processo de exportação de manga brasileira para o resto do mundo.

\section{METODOLOGIA}

O modelo de resposta binária é um caso especial de modelos com variáveis dependentes discretas, normalmente aplicado a estudos de contratos, cujo objetivo é apontar os determinantes que levam um produtor a utilizar ou não contratos frente às suas características de gestão e de comportamento.

Contudo, no presente estudo, além de averiguar a probabilidade de o agente "escolher" não conhecer (alternativa 0) ou escolher conhecer e utilizar a venda por contrato (alternativa 1), leva-se em consideração outro tipo de "escolha": a de conhecer e não utilizar tal mecanismo. Essa conduta estaria numa situação intermediária entre a opção de conhecer e utilizar a venda por contrato e o seu total desconhecimento, visto que: i) o conhecimento e a não utilização revelariam uma dificuldade do produtor em empregar tal mecanismo; e ii) ao mesmo tempo, o conhecimento e a não utilização demonstrariam um interesse do produtor pelo mercado de 
contratos, o que configura uma condição intermediária e mais favorável que o efetivo desconhecimento do mecanismo.

Nesse contexto, é analisada a probabilidade de o agente "escolher" uma entre três alternativas, como função de fatores observáveis: (i) não conhecimento do mercado de contratos, (ii) conhecimento e não utilização da venda por contrato ou (iii) conhecimento e utilização da venda por contrato. Para tal tipo de variável dependente, é adequada a aplicação do logit multinomial.

Segundo Greene (2003), não há evidências de que variáveis de escolha multinomial como essas estejam inerentemente em ordem, como acontece nos casos de ratings de títulos, de teste de gosto, de pesquisas de opinião, de nível de cobertura de seguro tomado por um consumidor (nenhum, parcial ou total), entre outros. Assim, para o caso específico deste trabalho (embora o resultado seja discreto), o logit multinomial pode contribuir bastante para contabilizar a natureza não ordinal da variável dependente.

\section{Modelo econométrico}

O modelo logit multinomial é construído a partir de uma regressão latente equivalente aos modelos binomiais tradicionais. A partir da função $Y^{*}=$ $X^{\prime} \beta+\varepsilon$, não há condições de observar $Y$, mas é possível observar que:

$$
Y=\left\{\begin{array}{cl}
0, & Y^{*} \leq \mu_{1} \\
1, & \mu_{1} \leq Y^{*} \leq \mu_{2} \\
2, & \mu_{2} \leq Y^{*} \leq \mu_{3} \\
& \cdots \\
J, & \mu_{J} \leq Y^{*}
\end{array}\right.
$$

em que os parâmetros $\mu$ são chamados pontos de corte das categorias, sendo desconhecidos e estimados em conjunto ao vetor $\beta$, enquanto $J$ refere-se ao número de categorias cuja variável dependente está dividida.

Conforme Greene (2003), o modelo logit multinomial é estimado pelo método de máxima verossimilhança. Contudo, os coeficientes estimados não representam diretamente as respostas marginais das variáveis explicativas e são de difícil interpretação. Assim, é necessário calcular os efeitos marginais que variam com o ponto de estimação, que é dado pela categoria base.

\section{Dados utilizados}

As informações relativas à conjuntura dos produtores no Vale do São Francisco constituem-se de dados primários obtidos através de uma pesquisa de campo financiada pela Fundação de Amparo à Ciência e Tecnologia do Estado de Pernambuco (FACEPE), através de questionários aplicados junto a 85 produtores de manga do Polo Petrolina-Juazeiro, durante os meses de outubro e novembro do ano de 2013. A pesquisa descreve dados de corte transversal para o ano agrícola de 2012/2013, com relação ao perímetro de irrigação Nilo Coelho. A população total de 
produtores de manga do perímetro Nilo Coelho é de 650 pessoas. Assim, a amostra de 85 produtores responde por 13,08\% do total do perímetro.

De todos os entrevistados, 71 possuem propriedade com tamanho inferior a 10 ha, e 14 possuem terras com extensão entre 10 e 30 ha (todas com áreas irrigadas inferiores a 10 ha - produtores de pequeno porte). A concentração das entrevistas com agricultores de pequeno porte vale-se da forte participação destes quando se considera o número de produtores que atuam em venda indireta por contrato. Nesse sentido, enfatiza-se que a amostra deve representar satisfatoriamente as características da região e pode sintetizar conclusões a respeito dos determinantes da decisão de utilizar ou não contratos de vendas entre seus produtores.

Vale salientar que as informações relativas à venda por contratos, tratadas na pesquisa, contemplam a situação dos contratos informais de venda estabelecidos entre os produtores de manga do perímetro Nilo Coelho e as empresas agrícolas exportadoras da fruta para a Europa e/ou para os Estados Unidos. O objetivo seria levantar informações quanto ao conhecimento e ao uso desse tipo de contrato por parte dos produtores de manga.

Nesse contexto, foram propostas três opções de escolha de resposta, mutuamente excludentes: i) não conhecimento do mercado de venda por contrato; ii) conhecimento do mercado de venda por contrato, mas sem sua utilização; e iii) conhecimento do mercado de venda por contrato com sua utilização. Dessa maneira, as relações que norteiam a venda por contrato serão analisadas de acordo com essas três categorias, conforme a resposta dada pelos produtores em cada questionário.

\section{Modelo empírico}

Com o objetivo de estimar a probabilidade de o produtor do Polo PetrolinaJuazeiro, dadas determinadas características, vir a conhecer e a realizar venda por contrato, considera-se como estratégia empírica a utilização de um modelo com variável dependente qualitativa multinomial. Ou seja, temse como resposta uma variável que assume o valor 0 para o produtor que não conhece o mercado de venda por contrato, o valor 1 para o produtor que conhece tal mercado, mas não o utiliza, e o valor 2 para o produtor que conhece o mercado de contratos e utiliza esse mecanismo de venda.

Assim, como a característica almejada é o conhecimento e a utilização do contrato, a categoria base do modelo logit multinomial será o grupo dos produtores que têm conhecimento do mercado de venda por contrato e o utiliza (categoria 2). Desse modo, serão estimadas duas regressões: uma para a categoria 0 (desconhecimento do mercado de contratos), e outra para a categoria 1 (conhecimento do mercado de contratos, mas sem usá-lo). Como a categoria 2 é utilizada como referência, coeficientes positivos no modelo significam que um aumento no fator explanatório tende a diminuir 
a propensão a conhecer o mercado de contrato e, paralelamente, a aumentar o não uso, mesmo com conhecimento desse mercado.

A lista de variáveis básicas utilizadas para a estimação de modelos empíricos dessa natureza está dividida em cinco vertentes principais: a primeira representa o porte do produtor, dado pela área total do lote, em hectares; a segunda descreve a sua capacidade de produção, dada pela produção de manga do lote (em quilogramas); a terceira analisa o alcance em educação/conhecimento que o produtor conquistou, dado pelo mais alto grau de escolaridade que ele atingiu (analfabeto, ensino fundamental, ensino médio/técnico ou ensino superior); a quarta descreve os anos de vida do produtor, considerada a sua idade; e a quinta e última vertente analisa a experiência do produtor em produzir manga, dada pelos anos em que ele se dedica ao cultivo da fruta.

As demais variáveis explicativas (variáveis auxiliares) podem ser subdivididas em categorias que contemplam características locacionais, de gestão e comportamentais do produtor. Essas variáveis são:

i. Variáveis de Localização: variáveis dummies para cada um dos onze núcleos do perímetro Nilo Coelho (N1 a N11)2;

ii. Características da Gestão do Negócio: oito variáveis dummies referentes a maneira como o produtor gerencia seu lote. As variáveis são: ter renda extra (fora da atividade agrícola), participar de treinamentos, contar com assistência técnica, participar de associação de produtores, plantar outras culturas, possuir interação com institutos de pesquisas, possuir certificação (GlobalGap) e possuir dívidas (com bancos públicos, CODEVASF ou distrito de irrigação).

iii. Características Comportamentais do Produtor: cinco variáveis referentes a maneira como o produtor encara o negócio da manga. Essas variáveis descrevem três pontos do seu comportamento quanto à sua relação com contratos: ter preferência por outro instrumento de gerenciamento de risco, confiar na intuição para avaliar o melhor momento para vender manga (propensão ao risco), considerar sua gestão administrativa superior à média dos demais produtores.

As três características comportamentais acima são avaliadas em uma escala Likert com cinco graus de concordância do produtor frente às afirmações em parênteses. Esses graus de concordância são: (1) discorda totalmente, (2) discorda parcialmente, (3) indiferente, (4) concorda parcialmente e (5) concorda totalmente.

Dessa forma, a situação da venda por contrato aqui tratada será contemplada como variável dependente, a ser regredida em função das diversas características relacionadas acima. Assim, será possível responder ao questionamento inicialmente levantado sobre quais fatores determinam o fenômeno da utilização da venda por contrato no Polo Petrolina-Juazeiro. Paralelamente, pode-se levantar apontamentos sobre o quanto os produtores são mais propensos a conhecer e utilizar o mercado de venda

2 O perímetro Senador Nilo Coelho é dividido em onze núcleos distintos, com particularidades quanto às distâncias ao centro urbano de Petrolina e de Juazeiro, ao perfil produtivo explorado, à disponibilidade de mão-de-obra etc. 
por contrato no caso da produção de manga (dados por seus efeitos marginais).

\section{RESULTADOS E DISCUSSÃO}

O modelo logit multinomial foi utilizado nesta pesquisa a fim de verificar o efeito das variáveis explicativas sobre a probabilidade de conhecimento e utilização de contrato por parte do produtor rural. Para tanto, utilizou-se o método de máxima verossimilhança $(M L)$, conforme apresentado na metodologia. Como referidos modelos são essencialmente heteroscedásticos, tornando os desvios-padrão estimados viesados, utilizou-se, para a estimação da matriz de variância-covariância dos resíduos, desvios-padrão robustos à heteroscedasticidade. De acordo com Greene e Zhang (2003), o uso de desvio-padrão robusto não altera os coeficientes estimados, entretanto, devido ao fato de que os erros-padrão são alterados, as estatísticas de teste fornecerão p-valores extremamente precisos.

A presente seção de resultados está dividida em duas partes principais: uma descrevendo o comportamento das características do produtor e sua variável dependente, e a outra analisando os resultados da estimação do modelo logit multinominal.

\section{Análise descritiva dos dados}

Para compreender os fatores que poderiam influenciar o conhecimento e a utilização do mercado de contratos entre os produtores avaliados na amostra, faz-se aqui uma prévia análise descritiva relacionando características do produtor à sua escolha de categoria da variável dependente ${ }^{3}$. As características aqui analisadas referem-se àquelas tratadas na seção "Modelo Empírico", com exceção das variáveis comportamentais (que serão apreciadas exclusivamente pelo modelo econométrico).

Considerando somente as três categorias da variável dependente, os dados mostram que $40,00 \%$ do total de produtores da amostra não conhecem o mercado de contratos, $48,24 \%$ conhecem o mercado e não o utilizam, e $11,76 \%$ conhecem e utilizam o mercado de contratos. A utilização de contratos ainda é restrita a uma pequena amostra de produtores do perímetro Nilo Coelho, concentrando-se em pouco mais de 11,00\% do total.

Inicialmente, ao se analisar a variável produção, verifica-se que não há uma relação clara entre ela e a variável dependente. De acordo com a Figura 1 (primeira linha de quadros, à esquerda), as médias de produção obtidas em cada categoria foram de aproximadamente $49.000 \mathrm{~kg}, 87.500 \mathrm{~kg}$ e $53.000 \mathrm{~kg}$, respectivamente. No total da amostra, a média da produção da propriedade é de $67.266,68 \mathrm{~kg}$, superior à dos produtores que "não conhecem o mercado

3 (i) não conhece o mercado de contratos, (ii) conhece e não utiliza o mercado de contratos e (iii) conhece e utiliza o mercado de contratos. 
de contratos" e inferior à dos que "conhecem e não utilizam o mercado de contratos". A média amostral, por sua vez, foi superior à dos que "conhecem e utilizam" contratos. A correlação linear entre essa variável e a variável dependente foi de 0,1567 .
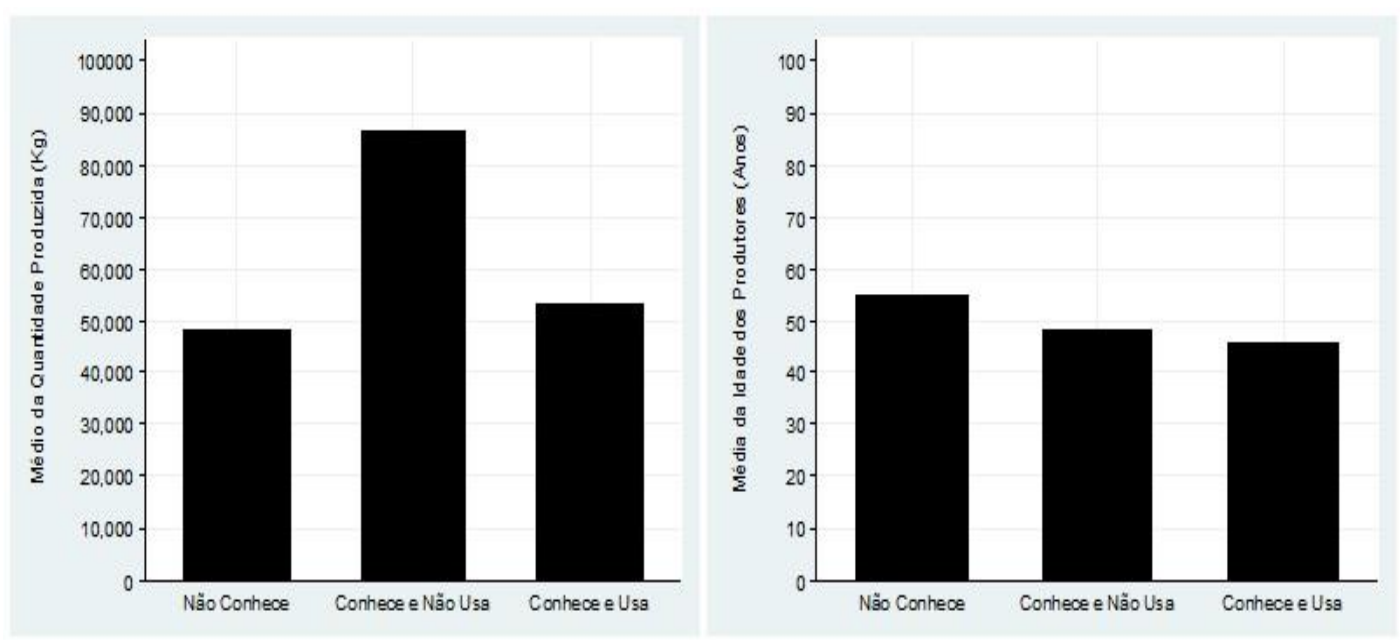

Figura 1. Relação entre a variável dependente, quantidade produzida e idade.

Fonte: Elaborado pelos autores.

Quanto à idade (Figura 1, primeira linha de quadros, à direita), verifica-se que há relação negativa entre essa variável e a propensão do produtor a conhecer o mercado de contratos e utilizá-lo. Dada a média amostral (50 anos), os produtores que "não conhecem" o mercado de contratos possuem em média 55 anos, enquanto que os produtores que "conhecem e não utilizam" apresentam idade média de 49 anos. Já os que "conhecem e utilizam" são mais jovens, com idade média de 47 anos.

Quanto ao acesso à assistência técnica, considerou-se, para a apresentação da Figura 2 (primeira linha de quadros, à esquerda), a relação da variável dependente com o grupo de produtores que obtiveram assistência técnica, levando em conta também o grupo daqueles que não tiveram acesso a essa assistência. Para estes, verifica-se uma relação negativa entre as variáveis, visto que 55,56\% desses produtores são caracterizados por não conhecerem o mercado de contratos, seguidos de $36,11 \%$ que conhecem e não utilizam o mercado de contratos e, enfim, de $8,33 \%$ que conhecem e utilizam esse mercado. Já entre os que afirmaram ter acesso à assistência técnica, 28,57\% são contados entre os que não conhecem o mercado de contratos; $57,14 \%$, entre os que conhecem e não o utilizam; e 14,29\%, entre os que conhecem e o utilizam. No total da amostra, 57,65\% receberam assistência técnica. A correlação entre essa variável e a variável dependente é igual a 0,2459.

A relação entre a variável dependente e a participação dos produtores em treinamentos (Figura 2, primeira linha de quadros, à direita) é negativa entre aqueles que não realizaram treinamento e positiva para os que realizaram treinamentos. Considerando os produtores que optaram por não 
realizar treinamentos, $48,48 \%$ se encontram entre os que não conhecem o mercado de contratos (sendo esse percentual de apenas 10,53\% entre os que participaram de treinamento).

Comparando ainda os grupos dos que realizaram ou não treinamentos, $42,42 \%$ dos produtores que não realizaram treinamentos conhecem e não utilizam o mercado de contratos (sendo esse percentual de $68,42 \%$ entre os que participaram de treinamento). Cerca de 9,10\% dos produtores que não participaram de treinamento conhecem e utilizam o mercado de contratos (esse percentual é de 21,55\% para os que participaram de treinamento). No total da amostra, 22,35\% dos produtores participaram de algum tipo de treinamento, mostrando que a aquisição de treinamentos tende a levar os produtores a conhecerem e utilizarem o mercado de contratos. O coeficiente de correlação linear entre essa variável e a variável dependente é de 0,3143.

A respeito da interação do produtor com instituições de pesquisa, a Figura 2 (segunda linha de quadros, à esquerda) indica que, entre os produtores que não possuem interação com institutos de pesquisas, a maior parte deles está centrada nas duas primeiras categorias da variável dependente (não conhecem o mercado de contratos ou conhecem e não o utilizam). Já entre os produtores que possuem interação com institutos de pesquisas, a amostra se encontra suavemente distribuída entre as três categorias da variável dependente.

Assim, quanto aos produtores que não conhecem o mercado de contratos, $42,03 \%$ estão contados entre os que não possuem relação com instituições de pesquisa (sendo esse percentual de 31,25\% entre os que interagem com esses institutos). Já entre os que conhecem e não utilizam o mercado de contratos, 49,28\% não possuem interação com institutos de pesquisas e $43,75 \%$ possuem. Com relação ao grupo dos que conhecem e utilizam o mercado de contratos, somente $8,69 \%$ não possuem interação com institutos de pesquisas (sendo esse percentual de $25,00 \%$ para os que possuem). No total da amostra, 18,82\% dos produtores demonstraram ter relação com instituições de pesquisa. O coeficiente de correlação linear dessa variável frente a variável dependente foi de 0,1600.

A distribuição dos produtores que estão filiados ou não a associações (Figura 2, segunda linha de quadros, à direita) mostra que aqueles que não estão filiados se encontram distribuídos de forma centrada nas duas primeiras categorias da variável dependente. Já para os produtores filiados a associações, essa distribuição se concentra nas duas últimas categorias.

Entre os produtores que não conhecem o mercado de contratos, 42,67\% não participam de associações (sendo esse percentual de $20,00 \%$ para os produtores que participam). Já para os que conhecem e não utilizam o mercado de contratos, 49,33\% não participam de associações e 40,00\% participam (percentuais próximos). Para os que conhecem e utilizam o mercado de contratos, 8,00\% não participam de associações e 40,00\% participam. Em toda a amostra, 9,41\% dos produtores participam de associações (e se pode deduzir que boa parte destes conhecem e utilizam o 
mercado de contratos). O coeficiente de correlação linear entre a variável associação e a variável dependente é de aproximadamente 0,2262.
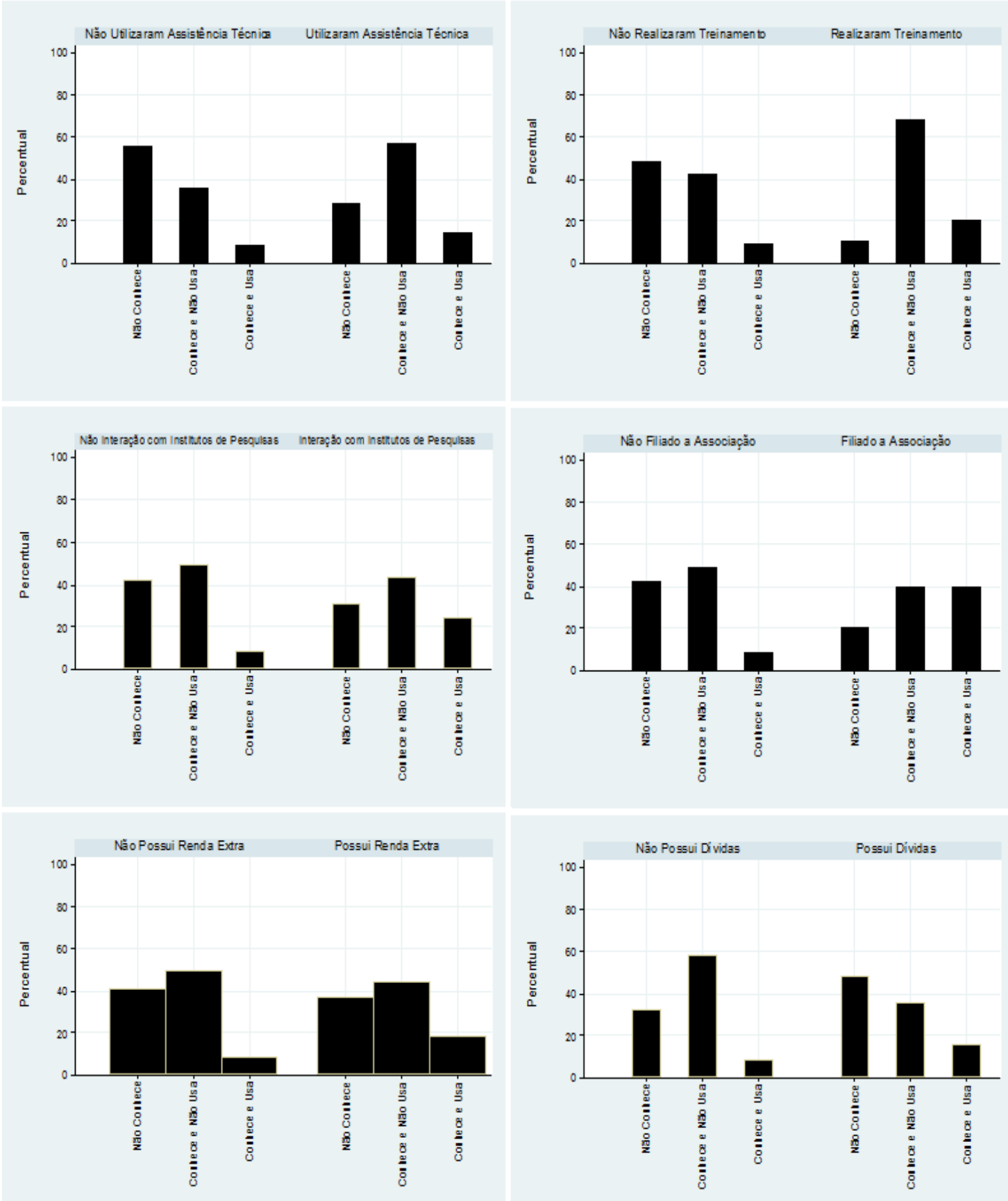

Figura 2. Relação entre a variável dependente e as características de gestão da propriedade.

Fonte: Elaborado pelos autores.

A distribuição de produtores quanto a variável renda extra está centrada nas duas primeiras categorias da variável dependente para ambos os grupos (os que possuem e os que não possuem renda extra). De acordo com a Figura 2 (terceira linha de gráficos, à esquerda), cerca de $41,38 \%$ dos produtores que afirmaram não conhecer o mercado de contratos não possuem renda extra (sendo esse percentual de 37,04\% para o caso dos produtores que possuem 
renda extra). Para os produtores que afirmaram conhecer e não utilizar o mercado de contratos, $50,00 \%$ não possuem renda extra e $44,44 \%$ possuem. Já entre os que conhecem e utilizam o mercado de contratos, 8,62\% não possuem renda extra e aproximadamente $18,52 \%$ possuem.

Assim, pode-se supor que a renda extra do produtor poderia promover (ou incentivar) o conhecimento e a venda por contratos. No total da amostra, $31,77 \%$ dos produtores afirmaram possuir renda extra. O coeficiente de correlação linear dessa variável frente a variável dependente é de 0,1002.

Já para a variável existência de dívidas, existe forte relação negativa entre os produtores que possuem dívidas. De acordo com a Figura 2 (terceira linha de quadros, à direita), há uma relação negativa visível para o caso dos produtores que possuem dívidas e uma distribuição bem heterogênea entre as três categorias da variável dependente para o grupo dos que não possuem. Analisando exclusivamente os produtores que não possuem dívidas, 32,61\% não conhecem o mercado de contratos, 58,70\% conhecem e não utilizam o mercado de contratos e $8,69 \%$ conhecem e utilizam esse mercado. Já entre os que possuem dívidas, esses percentuais foram de $48,72 \%, 35,90 \%$ e $15,38 \%$, respectivamente. Tomando como base o total da amostra, cerca de $45,88 \%$ dos produtores afirmaram possuir dívidas. $O$ coeficiente de correlação linear entre essa variável e a variável dependente é reduzido e negativo $(-0,0709)$.

A Figura 3, por seu turno, analisa a escolaridade do produtor. Os níveis de escolaridade considerados para análise são: (i) analfabeto, (ii) fundamental (incompleto e completo) e (iii) médio/técnico ou superiort. Entre os produtores que se declararam analfabetos, $77,78 \%$ não conhecem o mercado de contratos e $22,22 \%$ conhecem tal mercado e não o utilizam. Já entre os produtores que se enquadram no nível fundamental, tem-se percentuais idênticos para o grupo dos que não conhecem o mercado de contratos e para o grupo dos que conhecem o mercado e não o utilizam (46,51\%). Somente $6,98 \%$ dos produtores que se enquadram no nível fundamental conhecem e utilizam o mercado de contratos. Já entre os que possuem enquadramento escolar situado no ensino médio, técnico ou superior, esses percentuais são de $21,21 \%, 57,58 \%$ e $21,21 \%$ para cada uma das categorias da variável dependente, respectivamente.

A Figura 3 mostra claramente que, à medida que o nível de escolaridade vai avançando para um nível mais elevado, o conhecimento do mercado de contratos e a participação do produtor nesse mercado vai também aumentando gradativamente. Há forte indicação de que os níveis de escolaridade podem influenciar positivamente o produtor a conhecer o mercado de contratos e, posteriormente, a utilizá-lo. No total da amostra, $10,59 \%$ dos produtores se enquadram entre os analfabetos, $50,59 \%$, entre os de escolaridade fundamental e $38,82 \%$, entre os que possuem perfil escolar

${ }^{4}$ Essa junção de níveis de escolaridade visa a simplificar a análise gráfica, buscando identificar e analisar o enquadramento escolar do produtor. Na estimação do modelo logit multinomial propriamente dita utilizou-se os níveis de escolaridade descritos na Tabela 1. Revista de Economia e Agronegócio - REA | V. 15 | N. 3 | 2017 | pág. 417 
baseado no ensino médio, técnico ou superior. O coeficiente de correlação da variável escolaridade frente à variável dependente é de 0,3398.

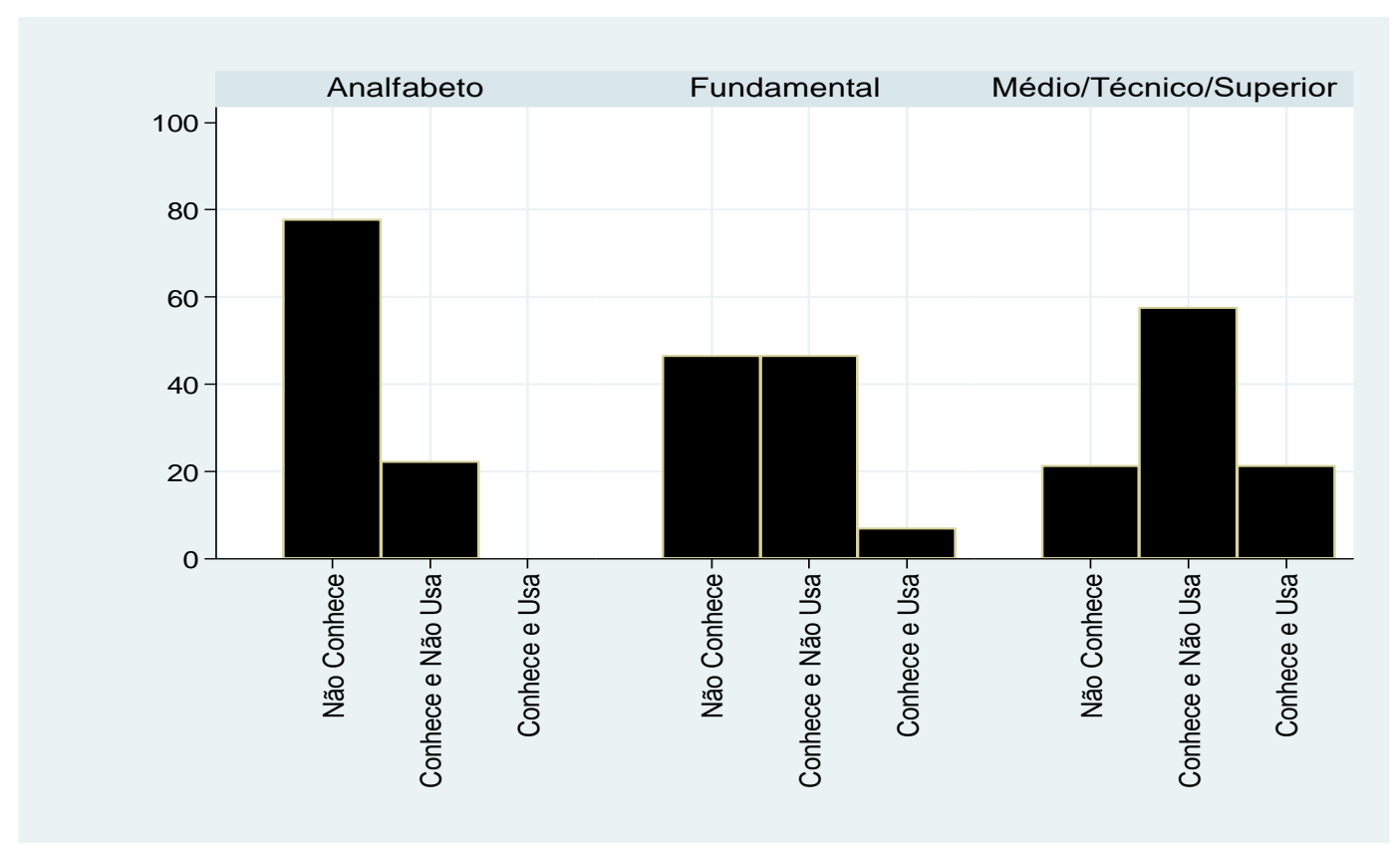

Figura 3. Relação entre a variável dependente e os níveis de escolaridade.

Fonte: Elaborado pelos autores.

\section{Modelo logit multinomial: diagnóstico da venda por contrato no pólo}

Os resultados obtidos para o modelo logit multinomial são descritos na Tabela 1. Como pode-se observar, a estatística $F$ aponta para modelos apropriados. Vale salientar que o tamanho da população considerado na análise foi de 650 produtores, com amostra de 85 selecionados. Conforme explicitado na seção "Modelo Empírico", são estimadas duas regressões (uma para a categoria 0 e outra para a categoria 1), sendo a categoria 2 (conhecimento e uso do mercado de contratos) a categoria de referência.

Ao se analisar os resultados obtidos na Tabela 1, pode-se verificar que, para o modelo $\ln \left(P_{0} \mid P_{2}\right)$ - não conhecimento do mercado de contratos -, foram significantes as variáveis analfabeto, ensino fundamental, treinamento, preferência por outro mecanismo de proteção e propensão ao risco, apresentando sinal positivo para as duas primeiras e negativo para as demais. No tocante ao modelo $\ln \left(P_{1} \mid P_{2}\right)$ - conhecimento e não uso do mercado de contratos as variáveis que se mostraram significantes foram $\ln ($ produção), analfabeto, ensino fundamental, associação, assistência técnica, existência de dívidas, preferência por outro mecanismo de proteção e propensão ao risco, com sinal positivo para as três primeiras e sinal negativo para as demais.

Desse modo, o fato de o produtor ser analfabeto ou possuir apenas o ensino fundamental completo poderia distanciá-lo do conhecimento e do uso do mercado de contratos (um resultado também observado na análise descritiva da variável escolaridade). Já o fato de o produtor ter recorrido à treinamento, ter preferência por outros mecanismos de proteção e também 
confiar em sua intuição para a venda (propensão ao risco) o leva a se aproximar do conhecimento do mercado de contratos (fato também observado na análise descritiva dessas variáveis).

Tabela 1. Estatísticas do modelo logit multinomial

\begin{tabular}{|c|c|c|c|c|}
\hline \multirow{2}{*}{ Discriminação } & \multicolumn{2}{|c|}{$\ln \left(P_{0} \mid P_{2}\right)$} & \multicolumn{2}{|c|}{$\ln \left(P_{1} \mid P_{2}\right)$} \\
\hline & Coeficientes & RRR & Coeficientes & RRR \\
\hline CONSTANTE & 11,0634 & 63791,74 & $-3,3611$ & 0,0347 \\
\hline $\ln$ (produção) & 0,6061 & 1,8332 & $1,7283^{* *}$ & 5,6310 \\
\hline Idade & 0,0262 & 1,0266 & 0,0153 & 1,0154 \\
\hline Analfabeto & $18,5153^{*}$ & $1,10 \mathrm{e}+08$ & $17,6852^{*}$ & $4,79 e+07$ \\
\hline Ensino fundamental & $17,2121^{*}$ & $2,99 e+07$ & $16,5897^{*}$ & $1,60 e+07$ \\
\hline Ensino médio e técnico & $-1,1167$ & 0,3274 & $-1,1762$ & 0,3085 \\
\hline Associação & $-3,6890$ & 0,0250 & $-4,2200 * *$ & 0,0147 \\
\hline Assistência técnica & $-0,0879$ & 0,9158 & $1,8703^{*}$ & 6,4903 \\
\hline Treinamento & $-3,6958^{* *}$ & 0,0248 & $-1,6565$ & 0,1908 \\
\hline Renda extra & $-0,1662$ & 1,1809 & 0,0113 & 1,0114 \\
\hline $\begin{array}{l}\text { Interação com } \\
\text { institutos de pesquisas }\end{array}$ & $-0,6319$ & 0,5316 & $-1,7687$ & 0,1706 \\
\hline Existência de dívidas & $-1,6204$ & 0,1978 & $-2,3864^{* *}$ & 0,0920 \\
\hline $\begin{array}{l}\text { Preferência por outro } \\
\text { mecanismo de } \\
\text { proteção }\end{array}$ & $-2,1135^{\star *}$ & 0,1208 & $-1,9623^{* *}$ & 0,1405 \\
\hline Propensão ao risco & $-2,1573^{* *}$ & 0,1156 & $-1,9405^{* *}$ & 0,1436 \\
\hline $\begin{array}{l}\text { Excesso de confiança } \\
\text { na própria gestão }\end{array}$ & 0,5186 & 1,6796 & 0,8589 & 2,3606 \\
\hline Estatística F(28, 57) & \multicolumn{2}{|c|}{$54,51^{*}$} & \multicolumn{2}{|c|}{$54,51^{*}$} \\
\hline $\begin{array}{c}\text { Tamanho da } \\
\text { população }\end{array}$ & \multicolumn{4}{|c|}{650} \\
\hline $\mathrm{N}^{\mathrm{l}}$ de observações & \\
\hline
\end{tabular}

Notas: RRR indica taxa relativa de risco; $\left({ }^{*}\right)$ significativo a $1 \% ;\left({ }^{* *}\right)$ significativo a $5 \%$.

Fonte: Elaboração própria.

No tocante aos produtores que conhecem o mercado de contratos, mas não o utilizam, a participação em associações poderia aumentar a chance desses produtores utilizarem tal mercado. Já o acesso à assistência técnica, a presença de dívidas (com CODEVASF, bancos públicos ou distritos de irrigação), bem como a preferência por outros mecanismos de proteção ou mesmo a confiança na intuição para o melhor momento de venda da produção, tendem a aproximar os produtores da utilização do mercado de contratos.

Contudo, ao se analisar a taxa relativa de risco (RRR), pode-se observar que, para as variáveis analfabeto e ensino fundamental (em ambos os modelos), a RRR é bastante elevada e explica mais a situação do modelo ligado aos produtores que desconhecem o mercado de contrato. Como ambas as variáveis são significantes em ambos os modelos, os impactos tendem a se 
anularem e não influenciarem os seus efeitos marginais. No modelo $\ln \left(P_{0} \mid P_{2}\right)$, as variáveis treinamento, preferência por outro mecanismo de proteção e propensão ao risco possuem RRR estimadas em 0,0248, 0,1208 e 0,1156, respectivamente, e tendem a explicar a situação do modelo adaptado aos produtores que conhecem mas não utilizam o mercado de contratos. $O$ mesmo ocorre com as variáveis associação, existência de dívidas, preferência por outro mecanismo de proteção e propensão ao risco no modelo $\ln \left(P_{1} \mid P_{2}\right)$, com RRR estimadas em 0,0147, 0,0920,0,1405 e 0,1436, respectivamente. A variável assistência técnica no modelo $\ln \left(P_{1} \mid P_{2}\right)$ possui RRR estimada em 6,4903 . Ou seja, poderia explicar (ou influenciar) mais a situação do modelo $\ln \left(P_{0} \mid P_{2}\right)$ do que a do seu próprio modelo.

Outro ponto a se levar em conta é o fato de as variáveis preferência por outro mecanismo de proteção e propensão ao risco serem também significantes em ambos os modelos. Assim como acontece com as variáveis analfabeto e ensino fundamental, essa mútua significância tende a anular seus efeitos em termos marginais em ambos os modelos.

Os efeitos marginais indicam o quanto a probabilidade de ocorrência em uma das categorias da variável dependente pode mudar diante de alterações em determinada variável explanatória, dados os dois modelos estimados. Para tanto, é necessário estipular uma condição inicial referente às características do produtor, o que normalmente é feito sobre um "produtor médio", que assumiria valores para as variáveis explicativas do modelo, correspondentes à média ou à moda amostral em cada variável. Assim, a análise dos efeitos marginais parte de um choque em certa característica do "produtor médio", para se verificar as alterações na distribuição de probabilidades de ocorrência em um dos modelos dado pela variável dependente.

Na amostra de 85 produtores, as médias e modas amostrais das variáveis explanatórias dispostas na Tabela 1 correspondem a: PRODUÇÃO = $67.266,68 \mathrm{~kg}$ (produção média de todos os produtores da amostra); IDADE $=50$ anos; ESCOLARIDADE = 2 (com Ensino Fundamental); ASSOCIAÇÃO = 0 (não participa de associação); ASSISTÊNCIA TÉCNICA $=1$ (conta com assistência técnica); TREINAMENTO $=0$ (não realiza treinamento); RENDA EXTRA = 0 (não possui renda extra); INTERAÇÃO COM INSTITUTOS DE PESQUISAS $=0$ (não possui interação com institutos de pesquisas); EXISTÊNCIA DE DÍVIDAS = 0 (não possui dívidas com bancos públicos, CODEVASF ou distrito de irrigação); MECANISMO DE PROTEÇÃO = produtores preferem outro mecanismo de proteção; PROPENSÃO AO RISCO = produtores confiam na intuição para o melhor momento de venda da produção; e EXCESSO DE CONFIANÇA NA GESTÃO = produtores acreditam que a sua gestão é superior à da média dos outros produtores. Todas essas variáveis são, portanto, as características do "produtor médio" do Polo Petrolina-Juazeiro.

A Tabela 2 descreve os efeitos marginais dos modelos $\ln \left(P_{0} \mid P_{2}\right)$ e $\ln \left(P_{1} \mid P_{2}\right)$. Como descrito acima, esses efeitos marginais levam em conta o impacto sobre o choque em uma das características do "produtor médio", e, assim, tentam verificar alterações na distribuição de probabilidade dos modelos 
$\ln \left(P_{0} \mid P_{2}\right)$ (o produtor vir a conhecer o mercado de contratos) e $\ln \left(P_{1} \mid P_{2}\right)$ (o produtor vir a utilizar o mercado de contratos). $\mathrm{O}$ nível de significância considerado para análise foi de 5,00\% e as variáveis significantes estão em negrito na Tabela 2.

Tabela 2. Efeitos marginais do modelo logit multinomial

\begin{tabular}{l|cc|cc}
\hline \multirow{2}{*}{\multicolumn{1}{c|}{ Discriminação }} & \multicolumn{2}{c|}{$\ln \left(P_{0} \mid P_{2}\right)$} & \multicolumn{2}{c}{$\ln \left(P_{1} \mid P_{2}\right)$} \\
\cline { 2 - 5 } & $\begin{array}{c}\text { Efeito } \\
\text { Marginal }\end{array}$ & P-valor & $\begin{array}{c}\text { Efeito } \\
\text { Marginal }\end{array}$ & P-valor \\
\hline $\ln$ (produção) & $-13,36 \%$ & 0,014 & $18,32 \%$ & 0,000 \\
Idade & $0,02 \%$ & 0,615 & $-0,10 \%$ & 0,793 \\
Analfabeto & $18,21 \%$ & 0,256 & $-4,92 \%$ & 0,757 \\
Ensino fundamental & $14,12 \%$ & 0,327 & $-1,23 \%$ & 0,932 \\
Ensino médio e técnico & $-0,96 \%$ & 0,938 & $-3,91 \%$ & 0,743 \\
Associação & $-2,84 \%$ & 0,828 & $-18,57 \%$ & 0,122 \\
Assistência técnica & $-25,92 \%$ & 0,004 & $29,95 \%$ & 0,001 \\
Treinamento & $-29,60 \%$ & 0,004 & $18,99 \%$ & 0,067 \\
Renda extra & $2,18 \%$ & 0,816 & $-1,93 \%$ & 0,831 \\
Interação com institutos & $12,80 \%$ & 0,402 & $-18,18 \%$ & 0,183 \\
de pesquisas & $7,05 \%$ & 0,404 & $-15,93 \%$ & 0,061 \\
Existência de dívidas & $-4,69 \%$ & 0,169 & $-2,82 \%$ & 0,447 \\
Preferência por outro & $-5,58 \%$ & 0,085 & $-1,94 \%$ & 0,557 \\
mecanismo de proteção & $-3,61 \%$ & 0,346 & $-6,36 \%$ & 0,084 \\
Propensão ao risco & & & \\
Excesso de confiança na & & &
\end{tabular}

Fonte: Elaboração própria.

Passando à análise dos efeitos marginais sobre os modelos $\ln \left(P_{0} \mid P_{2}\right)$ e $\ln \left(P_{1} \mid P_{2}\right)$, verifica-se que foram significantes as variáveis $\ln ($ produção), assistência técnica e treinamento no modelo $\ln \left(P_{0} \mid P_{2}\right)$, e as variáveis $\ln \left(\right.$ produção) e assistência técnica no modelo $\ln \left(P_{1} \mid P_{2}\right)$. De forma detalhada, vale ressaltar os seguintes pontos: (i) um choque positivo sobre a quantidade produzida leva o "produtor médio" a aumentar a chance de conhecer o mercado de contratos em 13,36\% (modelo $\ln \left(P_{0} \mid P_{2}\right)$ ). Por sua vez, a chance de utilizar o mercado de contratos, para essa mesma variável, é aumentada em 18,32\% (modelo $\ln \left(P_{1} \mid P_{2}\right)$ ); (ii) o acesso à assistência técnica aumentaria em 25,92\% a chance de o "produtor médio" conhecer o mercado de contratos, e em $29,95 \%$ a sua chance de utilizá-lo; (iii) a variável treinamento afetaria (em termos marginais) somente o modelo $\ln \left(P_{0} \mid P_{2}\right)$. Assim, caso o "produtor médio" venha a contar com treinamento, a chance de ele conhecer o mercado de contratos seria aumentada em $29,60 \%$.

A análise dos efeitos marginais de ambos os modelos mostram que um acréscimo positivo na variável $\ln ($ produção) poderia influenciar o "produtor médio" a conhecer o mercado de contratos em 13,36\%, e a utilizá-lo em $18,32 \%$. Já o acesso a assistência técnica teria impacto bem maior sobre 
ambas as chances (de conhecer o mercado de contratos e de utilizá-lo), sendo estimadas em $25,92 \%$ para o modelo referente aos produtores que não conhecem o mercado de contratos, e em $29,52 \%$ para os produtores que conhecem, mas não o utilizam. Do mesmo modo, o efeito é consideravelmente mais elevado quando o agente recorre a treinamento para gerir a produção. Nesse caso, sua chance de conhecer o mercado de contratos aumenta em $29,60 \%$.

Assim, para garantir que o "produtor médio" tenha chance de vir a conhecer o mercado de contratos, basta que o mesmo recorra à assistência técnica e ao treinamento junto aos órgãos de auxílio à agricultura irrigada na região do Polo Petrolina-Juazeiro. As utilizações dessas ferramentas garantiriam, como consequência, maior produção agrícola que, por sua vez, aumentaria ainda mais a chance de o "produtor médio" vir a conhecer e a utilizar o mercado de contratos. De forma idêntica, o acesso à assistência técnica levaria o "produtor médio" (supondo que o mesmo tenha conhecimento do mercado de contratos - modelo $\left.\ln \left(P_{1} \mid P_{2}\right)\right)$ a ter sua chance de utilizá-lo aumentada. Portanto, o acesso à assistência técnica e ao treinamento são as variáveis pertinentes para identificar (ou selecionar) o produtor com capacidade de conhecer e utilizar o mercado de contratos.

Vale enfatizar que o método logit multinomial é assintótico, ou seja, muitos dos seus pressupostos tendem a ser válidos em amostras grandes, o que não representa o caso do presente trabalho. Em amostras pequenas, o modelo logit multinomial apresenta dificuldade em interpretar certas variáveis como significantes quando seus verdadeiros efeitos são pequenos. Esse é o caso provável da variável assistência técnica (Tabela 1, coluna 1), estatisticamente não significante, mas com efeito marginal de grande magnitude, em torno de $25 \%$ (Tabela 2).

\section{CONCLUSÕES}

Diante dos resultados apresentados, verifica-se que a percepção dos produtores de manga do Polo Petrolina-Juazeiro, no tocante ao conhecimento e ao uso do mercado de contratos, está ainda aquém do que deveria estar. Esse resultado é ainda mais grave quando se percebe que esses produtores contam com uma tecnologia de irrigação que garante alto valor agregado para seus produtos, mas que não consegue garantir preços mais competitivos para essas produções (já que a venda por contratos é estabelecida por um monopsônio, a preços inferiores aos definidos pelo mercado exportador da fruta).

No tocante ao produtor médio, verifica-se que o mesmo não conta com treinamento para gerir sua produção e, provavelmente, possui uma assistência técnica intermitente, já que, ao que tudo indica, são essas variáveis que aproximariam tais produtores do conhecimento e do uso do mercado de contratos (ver efeitos marginais).

Além disso, os fatores determinantes da situação que abrange o conhecimento e a utilização do mercado de contratos são peculiares a cada tipo de modelo estimado. No caso do modelo que analisa os produtores que 
não conhecem o mercado de contratos, pesam positivamente as variáveis treinamento, preferência por outro mecanismo de proteção e propensão ao risco (confiança na intuição para o melhor momento de venda). Isso ocorre, talvez, pelo fato de essas variáveis levarem os produtores a obterem mais informações, no mercado, sobre o comportamento da produção e dos preços da manga que negociam. Paralelamente, baixos níveis de escolaridade dificultam o acesso a essas informações por parte dos

produtores e, consequentemente, aumentam suas chances de não conhecerem o mercado de contratos.

No caso do modelo que analisa os produtores que conhecem o mercado de contratos e não o utilizam, pesam positivamente o acesso à assistência técnica, a preferência por outro mecanismo de proteção e a propensão ao risco. Baixos níveis de escolaridade e filiação a associação aumentam suas chances de não utilizar o mercado de contratos.

Vale destacar que a análise do modelo logit multinomial aponta para a situação geral de conhecimento e uso do mercado de contratos no Polo Petrolina-Juazeiro. Ademais, os diagnósticos de ajuste dos dois modelos estimados apontam para níveis satisfatórios, que permitem a utilização dos mesmos para inferir sobre a influência da venda por contratos associada a determinado produtor que se deseja estudar, diante de suas características.

O presente trabalho não pode deixar de considerar a possibilidade de que alguns dos seus resultados sejam influenciados por fatores não observáveis ao modelo (variáveis omitidas ou presença de certo grau de simultaneidade entre algumas dessas variáveis). Assim, os resultados devem ser interpretados como uma associação entre a variável dependente e as independentes, e não como uma relação de causa e efeito.

Ante ao acima exposto, o foco de políticas setoriais deve recair sobre os seguintes aspectos: i) promover o acesso dos produtores a técnicas produtivas que elevem a produtividade dos cultivos explorados; ii) estimular a adequação dos produtores aos níveis de tecnologia e qualidade exigidos internacionalmente, visando a inserção (direta) do produtor no mercado exportador de manga; e, iii) promover medidas voltadas à melhoria da qualidade de ensino dos jovens produtores na região, principalmente do ensino técnico aplicado à agricultura, com potenciais efeitos de longo prazo. Para que a problemática atual da falta do uso de venda por contratos seja contornada, é necessário que medidas nesse sentido sejam colocadas em prática, com o objetivo de se buscar, de maneira responsável e construtiva, uma solução racional e justa, com a participação e o envolvimento dos produtores e seus agentes relacionados (sociedade e governo).

\section{REFERÊNCIAS}

ASPLUND, N. M.; FORSTER, D. L.; STOUT, T. T. Farmers' use of forward contracting and hedging. Review of Futures Markets, v. 8, p. 24-37, 1989. 
CODEVASF, Companhia de Desenvolvimento dos Vales do São Francisco e do Parnaíba. Home page. Disponível em: http://www.codevasf.gov.br/ Acesso em: 10 março de 2013.

CRUZ JÚNIOR, J. C.; SCOTT, I. H.; MARQUES, P. V.; MARTINES FILHO, J. G.; BACCHI, M. R. P. O excesso de confiança dos produtores de milho no Brasil e o uso de contratos futuros. Revista de Economia e Sociologia Rural, v. 49, n. 2, p. 369-390, 2011.

DAVIDSON, R.; MacKINNON, J. Econometric theory and methods. Oxford University Press, New York, 2003.

GOODWIN, B. K.; SCHROEDER, T. C. Human capital, producer education programs, and the adoption of forward-pricing methods. American Journal of Agricultural Economics, v. 76, n. 4, p. 936-947, 1994.

GREENE, W.H. Econometric Analysis, 5.ed. Prentice Hall, New Jersey, 2003.

ISENGILDINA, O.; HUDSON, M. D. Factors affecting hedging decisions using evidence from the cotton industry. In: NCR-134 Conference on Applied Commodity Price Analysis, Forecasting, and Market Risk Management, St. Louis, Missouri, 2001.

LIMA, R. C. e FERREIRA-IRMÃO, J. Coordenação vertical e contratos informais na agricultura irrigada: um estudo de caso com aplicação do modelo Tobit, Revista de Economia e Agronegócio, v. 2, n¹, 2004.

MAKUS, L. D.; LIN, B. H.; CARLSON, J.; KREBILL-PRATHER, R. Factors influencing farm level use of futures and options in commodity marketing. Agribusiness, v. 6, n. 6, p. 621-631, 1990.

MINISTÉRIO DO DESENVOLVIMENTO INDÚSTRIA E COMÉRCIO EXTERIOR (MDIC), www.aliceweb2.mdic.gov.br, Acessado em 12 de outubro de 2013.

PENNINGS, J. M. E.; LEUTHOLD, R. M. The role of farmer's behavioral attitudes and heterogeneity in futures contracts usage. American Journal of Agricultural Economics, v. 82, n. 4, p. 908-919, 2000.

SAMPAIO, L. M. B. Modelo Principal-Agente para Contratos entre Pequenos Produtores e Empresa Exportadora de Manga no Rio Grande do Norte, Revista de Economia e Sociologia Rural, v. 45, nº 4, Pag. 879-898, outubro-dezembro, 2007.

SHERRICK, B. J.; BARRY, P. J.; SCHNITKEY, G. D.; ELLINGER, P. N.; WANSINK, B. Farmers' preference for crop insurance attributes. Review of Agricultural Economics, v. 25, n. 2, p. 415-429, 2003.

SHAPIRO, B. I.; Brorsen, B. W. Factors affecting farmers' hedging decisions. North Central Journal of Agricultural Economics, v. 10, p. 145-153, 1988.

TURVEY, C.G., BAKER, T.G. A farm level financial analysis of farmers' use of futures and options under alternative farm programs. American Journal of Agricultural Economics, v. 72, p. 946-57, 1990. 